\title{
Double-Balloon Endoscopy-Assisted Balloon Dilation of Strictures Secondary to Small-Intestinal Lymphoma
}

\author{
Shogo Magome ${ }^{1}$, Hirotsugu Sakamoto ${ }^{1}$, Satoshi Shinozaki ${ }^{1,2}$, Masahiro Okada ${ }^{1}$, Tomonori Yano ${ }^{1}$, Keijiro Sunada ${ }^{1}$, \\ Alan Kawarai Lefor ${ }^{3}$ and Hironori Yamamoto ${ }^{1}$ \\ ${ }^{1}$ Division of Gastroenterology, Department of Medicine, Jichi Medical University, Shimotsuke, Tochigi, ${ }^{2}$ Shinozaki Medical Clinic, Utsunomiya, \\ Tochigi, ${ }^{3}$ Department of Surgery, Jichi Medical University, Shimotsuke, Tochigi, Japan
}

The gastrointestinal tract is the most common site of extranodal involvement of non-Hodgkin's lymphoma, and the small intestine is the second most common site following the stomach. ${ }^{1}$ Small-intestinal lymphoma is sometimes complicated by strictures, which have been usually managed with surgical resection. In recent years, balloon-assisted endoscopy has enabled the diagnosis of small-intestinal lymphoma before surgery, as well as the evaluation of tumor distribution throughout the gastrointestinal tract. ${ }^{2}$ There have been several reports describing the usefulness of endoscopic balloon dilation (EBD) with balloon-assisted endoscopy for small-intestinal strictures that develop during or after chemotherapy. ${ }^{3-5}$ Generally, EBD is contraindicated for strictures due to malignancies because perforation resulting from EBD has the potential to cause tumor dissemination in the peritoneal space. Chemotherapy is the first-choice treatment for small-intestinal lymphomas because the rate of initial response to chemotherapy is relatively high. ${ }^{2}$ Therefore, endoscopic treatment of small-intestinal strictures caused by lymphoma may be a reasonable alternative to surgery, as long as it can be performed safely. The aim of this study was to review the efficacy and safety of EBD for strictures secondary to small-intestinal lymphoma.

Received: December 16, 2018 Revised: February 6, 2019

Accepted: March 8, 2019

Correspondence: Hironori Yamamoto

Division of Gastroenterology, Department of Medicine, Jichi Medical University, 3311-1 Yakushiji, Shimotsuke, Tochigi 329-0498, Japan

Tel: +81-285-58-7347, Fax: +81-285-40-6598, E-mail: ireef@jichi.ac.jp

ORCID: https://orcid.org/0000-0002-3601-1153

cc This is an Open Access article distributed under the terms of the Creative Commons Attribution Non-Commercial License (http://creativecommons.org/ licenses/by-nc/3.0) which permits unrestricted non-commercial use, distribution, and reproduction in any medium, provided the original work is properly cited.
A total of 2,081 patients underwent double-balloon endoscopy (DBE) from April 2005 to January 2017 at Jichi Medical University Hospital, and their medical records were retrospectively reviewed. Of the 2,081 patients, 55 had a histological diagnosis of small-intestinal lymphoma based on endoscopic biopsy or surgical specimens. Follow-up data were available for 41 patients. Of these 41 patients, 10 developed symptomatic small-intestinal obstruction secondary to small-intestinal lymphoma. Of the 10 patients, 9 patients had a single stricture and 1 patient had 2 episodes of small-intestinal obstruction caused by separate metachronous strictures. In all cases, the cause of intestinal obstruction was observed with DBE, and failure to pass the endoscope was defined as a stricture. The indication for DBE-assisted EBD was a stricture causing obstructive symptoms, without an apparent deep ulcer that could extend to the muscularis, without severe angulation, and with a length of $<30 \mathrm{~mm}$. Of 10 patients with strictures, 5 patients were treated with DBE-assisted EBD (Fig. 1).

DBE-assisted EBD was carried out using a therapeutic endoscope (EN-450T5/W, EN-580T; Fujifilm, Tokyo, Japan) with a distal attachment (DH-17EN, Fujifilm). A throughthe-scope balloon catheter (CRE PRO GI wire guided; Boston Scientific, Natick, MA, USA) was inserted over a guidewire (enclosed guidewire or Revowave RWSA-3555I; Piolax Medical Devices, Yokohama, Japan) under fluoroscopic guidance. The balloon was slowly and carefully inflated with diluted contrast material and maintained in place for $1 \mathrm{~min}$ at the appropriate pressure under direct vision (Supplementary Video 1). The dilation diameter was increased in a stepwise manner. In patients who did not achieve complete remission after chemotherapy or in whom the diagnosis had not been confirmed, the dilation diameter was limited to $10 \mathrm{~mm}$ to re- 
duce the risk of perforation. In patients with complete remission after chemotherapy, the dilation diameter was gradually increased to $12-18 \mathrm{~mm}$ to facilitate long-term patency. EBD was performed after the resolution of obstructive symptoms by limiting oral intake. Before the EBD procedure, all patients underwent computed tomography to confirm the location of the stricture and to determine the optimal insertion route. The need for surgical intervention, occurrence of adverse events, short-term resolution of obstruction, occurrence of recurrence of intestinal obstruction, and EBD-free interval were assessed. The EBD-free interval was defined as the duration between the final EBD and the last clinic visit. This review was approved by the institutional review board.

Of the 5 patients treated with DBE-assisted EBD, 3 underwent EBD before achieving complete remission (2 before chemotherapy and 1 while receiving chemotherapy), and 2 underwent $\mathrm{EBD}$ after achieving complete remission with chemotherapy. The patient characteristics are shown in Table 1. The endoscopic images before and after the initial DBE-assist- ed EBD are shown in Fig. 2.

Three patients underwent EBD before achieving complete remission and had a single stricture secondary to small-intestinal lymphoma. Two of these patients (Patients 1 and 2) had an initial DBE-assisted EBD before the diagnosis of small-intestinal lymphoma was established. The other patient (Patient 3) developed a jejunal stricture due to relapse of follicular lymphoma. After starting chemotherapy, this patient had recurrent small-intestinal obstruction that was treated with DBE-assisted EBD. The dilation diameter of the initial EBD in these 3 patients was $<10 \mathrm{~mm}$. After achieving complete remission following treatment with chemotherapy, we gradually increased the diameter of dilation to $12-18 \mathrm{~mm}$.

Two patients underwent an initial DBE-assisted EBD after achieving complete remission following treatment with chemotherapy. One of these 2 patients (Patient 4) developed obstructive symptoms due to a jejunal stricture that developed after chemotherapy for diffuse large B-cell lymphoma. The development of restenosis has not been confirmed, with only

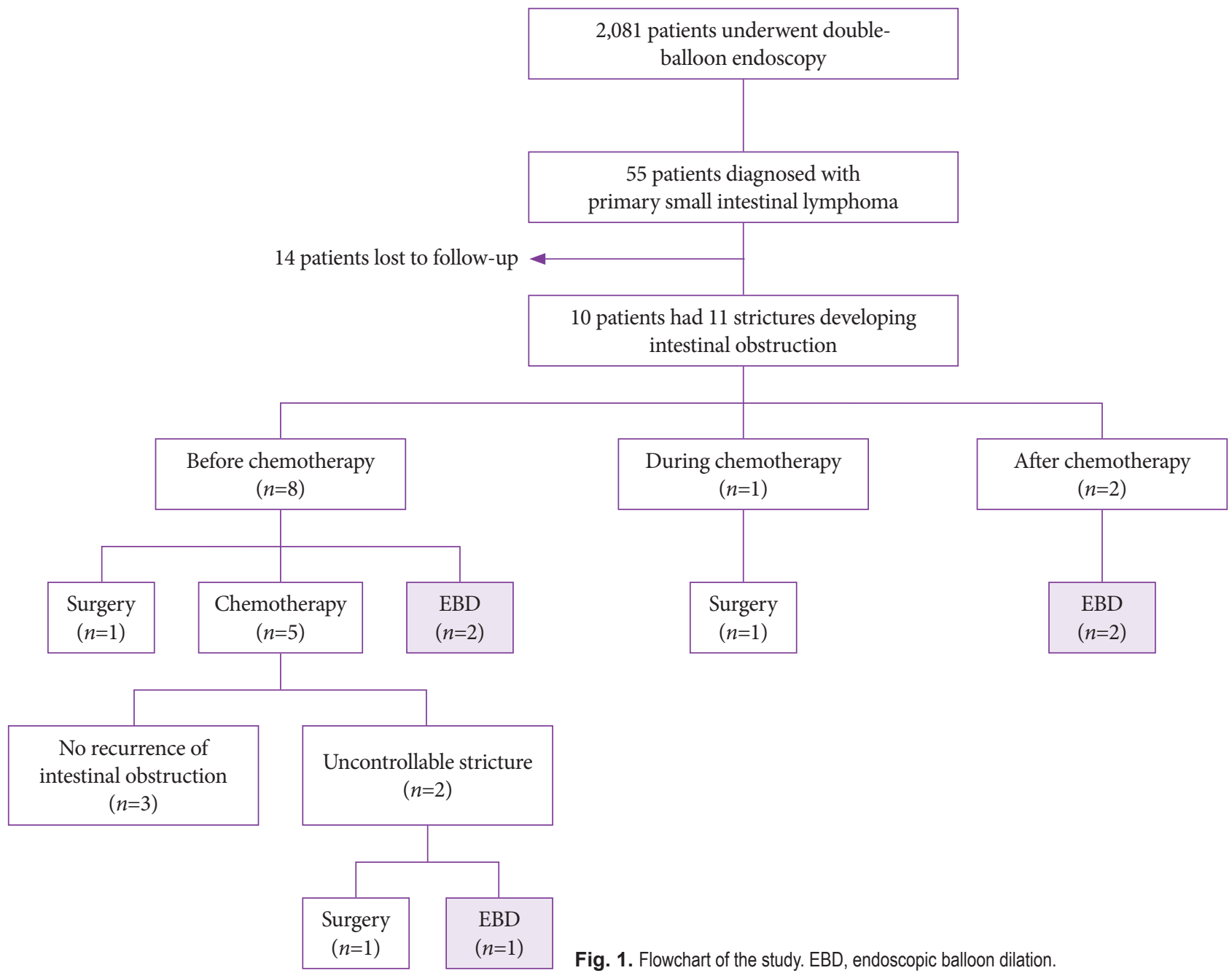


1 DBE-assisted EBD performed, for 14 months. The other patient (Patient 5) developed obstructive symptoms due to a jejunal stricture while receiving chemotherapy for follicular lymphoma, and underwent DBE-assisted EBD after completing chemotherapy and achieving a complete remission. After the second EBD, there was no relapse of symptoms and no restenosis for 21 months.

A total of 13 DBE-assisted EBD procedures were performed for the 5 patients. The median follow-up interval between the first DBE-assisted EBD and the last clinic visit was 29 months (range, 10-130 months). Although 3 patients had a recurrence of intestinal obstruction, these strictures could be managed with DBE-assisted EBD. Surgery was not needed for any patient during the follow-up, and no adverse events occurred. All DBE-assisted EBD procedures resulted in the short-term resolution of obstruction, and the EBD free interval was 21 months (range, 9-85 months).

This series shows that strictures secondary to small-intestinal lymphoma can be safely treated with DBE-assisted EBD as an alternative to surgery. To the best of our knowledge, this is the first report showing the effectiveness of EBD for strictures caused by small-intestinal lymphoma, with long-term follow-up data.

In patients who achieve complete remission after chemotherapy for lymphoma, DBE-assisted EBD has the potential to provide long-term patency as long as complete remission is maintained. DBE-assisted EBD is already recognized as a safe alternative to surgery in patients with benign small-intestinal strictures secondary to Crohn's disease. ${ }^{6,7}$ As long as complete remission is achieved with chemotherapy, the strictures are considered benign fibrotic strictures. As inflammation generally does not reoccur in the strictures, restenosis after EBD is rare. However, the occurrence of perforation has been reported following EBD with an 18-mm balloon, performed for a stricture secondary to small-intestinal lymphoma after complete remission. ${ }^{8}$ Therefore, EBD for small-intestinal strictures should be performed carefully in a stepwise fashion to prevent perforation. The optimal EBD diameter in the small intestine has not been strictly defined even in patients with strictures due to Crohn's disease. ${ }^{6}$ In the present series, we tried to dilate to $15 \mathrm{~mm}$, which is safe and provides long-term patency.

EBD is generally contraindicated for strictures due to

Table 1. Characteristics of Five Patients with a Stricture Secondary to Small Intestinal Lymphoma Who Were Treated with Double-Balloon Endoscopy-Assisted Endoscopic-Balloon Dilation

\begin{tabular}{|c|c|c|c|c|c|}
\hline \multirow[b]{2}{*}{ Patient } & \multicolumn{3}{|c|}{$\begin{array}{c}\text { DBE-assisted EBD } \\
\text { before complete remission }\end{array}$} & \multicolumn{2}{|c|}{$\begin{array}{c}\text { DBE-assisted EBD } \\
\text { after complete remission }\end{array}$} \\
\hline & 1 & 2 & 3 & 4 & 5 \\
\hline Age, yr & 60 & 68 & 68 & 62 & 49 \\
\hline Gender & Male & Male & Male & Male & Female \\
\hline Histology & $\begin{array}{l}\text { Follicular } \\
\text { lymphoma }\end{array}$ & $\begin{array}{l}\text { Marginal zone } \\
\text { lymphoma }\end{array}$ & $\begin{array}{l}\text { Follicular } \\
\text { lymphoma }\end{array}$ & $\begin{array}{c}\text { Diffuse large } \\
\text { B-cell lymphoma }\end{array}$ & $\begin{array}{l}\text { Follicular } \\
\text { lymphoma }\end{array}$ \\
\hline Lugano classification & Stage II1 & Stage II1 & Stage II2 & Stage IV & Stage IV \\
\hline Number of the stricture & 1 & 1 & 1 & 1 & 1 \\
\hline Location of the stricture & Jejunum & Jejunum & Jejunum & Jejunum & Jejunum \\
\hline Timing of the initial EBD & $\begin{array}{c}\text { Before } \\
\text { chemotherapy }\end{array}$ & $\begin{array}{c}\text { Before } \\
\text { chemotherapy }\end{array}$ & $\begin{array}{c}\text { During } \\
\text { chemotherapy }\end{array}$ & $\begin{array}{c}\text { After } \\
\text { chemotherapy }\end{array}$ & $\begin{array}{c}\text { After } \\
\text { chemotherapy }\end{array}$ \\
\hline $\begin{array}{l}\text { Dilation diameter } \\
\text { of the initial EBD, mm }\end{array}$ & 10 & 8 & 10 & 13.5 & 15 \\
\hline $\begin{array}{l}\text { Length of the stricture } \\
\text { at the initial EBD, mm }\end{array}$ & 20 & 10 & 15 & 5 & 5 \\
\hline $\begin{array}{l}\text { Total number of EBDs during } \\
\text { the follow-up period, times }\end{array}$ & 4 & 4 & 2 & 1 & 2 \\
\hline $\begin{array}{l}\text { Mean procedure time }{ }^{\mathrm{a})} \\
\text { min (range) }\end{array}$ & $\begin{array}{c}55.8 \\
(38-83)\end{array}$ & $\begin{array}{c}45.8 \\
(44-49)\end{array}$ & $\begin{array}{c}35.5 \\
(30-41)\end{array}$ & 20 & $\begin{array}{c}70 \\
(70)\end{array}$ \\
\hline EBD free interval, mo & 27 & 85 & 9 & 14 & 21 \\
\hline $\begin{array}{l}\text { Follow-up duration } \\
\text { after the initial EBD, mo }\end{array}$ & 60 & 130 & 10 & 14 & 29 \\
\hline
\end{tabular}

DBE, double-balloon endoscopy; EBD, endoscopic balloon dilation.

${ }^{\text {a) }}$ Procedure time is defined as the time from insertion to removal of the endoscope. 

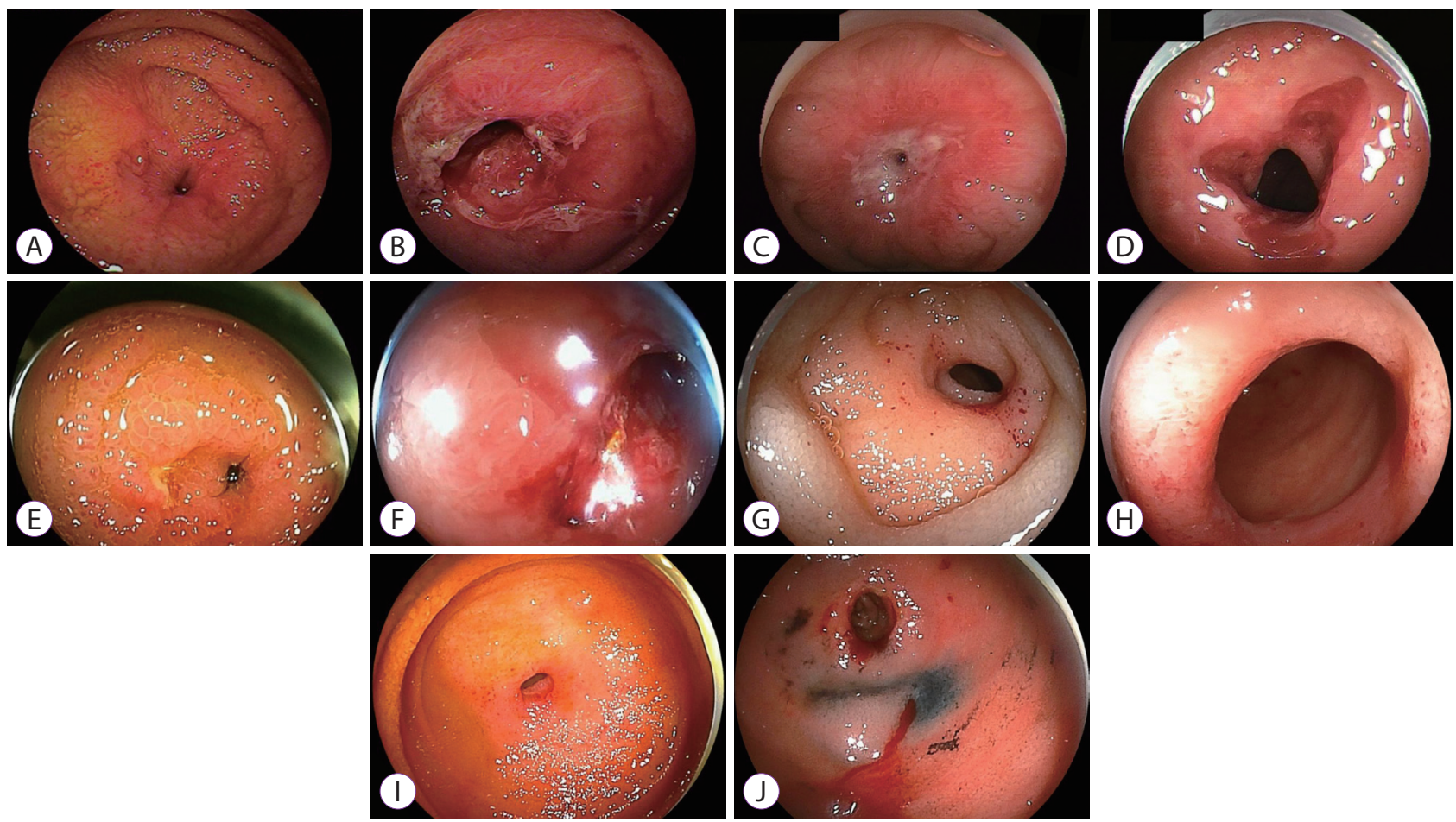

Fig. 2. Endoscopic images of 5 cases before and after initial double-balloon endoscopy (DBE)-assisted endoscopic balloon dilation (EBD). (A) Patient 1 has a 2-mm stricture due to follicular lymphoma before an initial DBE-assisted EBD. (B) Patient 1: after an initial DBE-assisted EBD. (C) Patient 2 has a 4-mm stricture due to marginal zone lymphoma before an initial DBE-assisted EBD. (D) Patient 2: after an initial DBE-assisted EBD. (E) Patient 3 has a 4-mm stricture due to follicular lymphoma before an initial DBE-assisted EBD. The mucosa was edematous. (F) Patient 3: after an initial DBE-assisted EBD. (G) Patient 4 has a 6-mm stricture due to diffuse large B-cell lymphoma before an initial DBE-assisted EBD. (H) Patient 4: after an initial DBE-assisted EBD. (I) Patient 5 has a 9-mm stricture due to follicular lymphoma before an initial DBE-assisted EBD. (J) Patient 5: after an initial DBE-assisted EBD.

malignancies because of the risk of perforation, which has the potential to result in peritoneal dissemination, especially in patients who have not yet achieved complete remission. Unlike other gastrointestinal malignancies, the first-line treatment for primary small-intestinal lymphoma is chemotherapy rather than surgical resection. Therefore, we believe that the use of DBE-assisted EBD is justified even before a patient has achieved complete remission. The primary purpose of EBD before complete remission is not to provide long-term patency but to prevent a bowel obstruction and allow the patient to complete the course of chemotherapy even with dietary restriction. In the present series, 3 patients were treated with DBE-assisted EBD before or while receiving chemotherapy. These 3 patients had localized indolent B-cell lymphoma, which has been reported unlikely to cause perforation in its natural course. ${ }^{9}$ To reduce the risk of perforation, we consider strictures with deep ulcers that may involve the muscularis as a contraindication to EBD, and we limit the dilation diameter to $10 \mathrm{~mm}$. Additionally, a stepwise and slow dilation is recommended to avoid perforation. This prudent strategy allows the patient to subsequently undergo chemotherapy without the need for a surgical intervention.

This study has some limitations. It is a retrospective study from a single center, and there is no comparison with surgical treatment of a stricture. However, the level of invasiveness is different between EBD and surgery, and it is not justifiable to perform a randomized-controlled trial including a control group treated surgically. Moreover, the number of included patients was small. Further large studies are necessary.

In conclusion, DBE-assisted EBD treatment of strictures secondary to small-intestinal lymphoma with a favorable histology or in complete remission may provide favorable outcomes. To minimize the potential risk of perforation, a stepwise dilation from a thin diameter may be crucial. DBE-assisted EBD has the potential to be a viable alternative to surgery. Recurrence of strictures after EBD can be managed with repeat EBD. DBE-assisted EBD before a patient achieves complete remission may be acceptable.

\section{Conflicts of Interest}

Hironori Yamamoto has patents for the double-balloon endoscope described in this article. Hironori Yamamoto also has a consultant relationship in Fujifilm Co., and has received honoraria, grants and royalties from the company. Hirotsugu Sakamoto, Keijiro Sunada, Hironori Yamamoto and Tomonori Yano have received honoraria from Fujifilm Co. The other authors have no financial conflicts of interest. 


\section{Author Contributions}

Conceptualization: Shogo Magome, Hirotsugu Sakamoto, Tomonori Yano, Hironori Yamamoto

Data curation: SM, Masahiro Okada, HS

Project administration: SM, HS

Supervision: HY

Validation: HS, MO, TY, Satoshi Shinozaki, Keijiro Sunada, Alan Kawarai Lefor, $\mathrm{HY}$

Writing-original draft: SM

Writing-review\&editing: HS, MO, TY, SS, KS, AKL, HY

\section{Supplementary Material}

Video 1. Double-balloon endoscopy-assisted endoscopic balloon dilation for small-intestinal strictures secondary to small-intestinal lymphoma in Patient 5 (https://doi.org/10.5946/ce.2019.015.v001).

\section{REFERENCES}

1. Chen Y, Chen Y, Chen S, et al. Primary gastrointestinal lymphoma: a retrospective multicenter clinical study of 415 cases in Chinese province of Guangdong and a systematic review containing 5075 Chinese patients. Medicine (Baltimore) 2015;94:e2119.

2. Kobayashi H, Nagai T, Omine K, et al. Clinical outcome of non-surgical treatment for primary small intestinal lymphoma diagnosed with double-balloon endoscopy. Leuk Lymphoma 2013;54:731-736.

3. Coumaros D, Tsesmeli N, Tzilves D. Diffuse large B-cell lymphoma complicated with jejunal stricture: the palliative role of double-balloon enteroscopy. Am J Gastroenterol 2008;103:2656-2657.

4. Honzawa Y, Kondo M, Hayakumo T, Matsuura M, Nakase H. Successful endoscopic dilation treatment of small intestinal stricture occurring during chemotherapy for malignant lymphoma. Case Rep Gastroenterol 2010;4:323-329.

5. Tamura H, Ogata K, Kondo A, et al. [Double balloon endoscopy as a useful tool for the diagnosis and treatment of four cases of primary small intestinal lymphoma]. Rinsho Ketsueki 2007;48:510-513.

6. Sunada K, Shinozaki S, Nagayama M, et al. Long-term outcomes in patients with small intestinal strictures secondary to Crohn's disease after double-balloon endoscopy-assisted balloon dilation. Inflamm Bowel Dis 2016;22:380-386

7. Hirai F, Andoh A, Ueno F, et al. Efficacy of endoscopic balloon dilation for small bowel strictures in patients with Crohn's disease: a nationwide, multi-centre, open-label, prospective cohort study. J Crohns Colitis 2018;12:394-401

8. Cho E, Uno K, Tanaka K, Yasuda K, Nakajima M. A case with perforation after endoscopic balloon dilatation for stricture of malignant lymphoma. Dig Endosc 2004;16(Suppl 1):S73-S75.

9. Vaidya R, Habermann TM, Donohue JH, et al. Bowel perforation in intestinal lymphoma: incidence and clinical features. Ann Oncol 2013;24:2439-2443. 